\title{
ANALISA SEBARAN ILUMINASI CAHAYA PETROMAKS DENGAN PERLAKUAN BERTUDUNG DAN TANPA TUDUNG
}

\author{
Wilhelmina Patty \\ Staf Pengajar pada Program Studi Pemanfaatan Sumberdaya Perikanan, \\ Fakultas Perikanan dan IImu Kelautan UNSRAT, Manado, 95115.
}

\begin{abstract}
Petromaks lights are often used by fishermen as fishing tools. Transmitting light petromaks much influenced by various factors one of those is fading (attenuation). The purpose of this paper is to understand the distribution of light transmitting petromaks and factors influencing it. The result showed that the illumination of light shade petromaks which light transmitting distance range further $( \pm 8 \mathrm{~m})$ than petromaks lights that are not covered $( \pm 21 \mathrm{~m})$. The constant fading (attenuation) of light is also greater $(0.78)$ for light petromaks hooded lamp from the lamp to petromaks without hood $(0: 24)$.
\end{abstract}

Key words: light illumination petromaks, attenuation, transmitting

\section{PENDAHULUAN}

Salah satu faktor yang sangat menentukan keberhasilan operasi penangkapan ikan adalah cahaya. Fungsi cahaya di sini adalah sebagai alat pemikat ikan untuk datang, khususnya untuk ikan yang bersifat fototaksis positif.

Tipe lampu petromaks yang biasanya digunakan oleh nelayan dalam operasi penangkapan dengan alasan harganya murah, suku cadang banyak tersedia, cara pengoperasian dan perawatannya mudah.

Penggunaan petromaks oleh nelayan selama ini dilakukan terkadang tidak sesuai dengan aturan yang diberikan oleh pabrik pembuatnya. Perlakuan tersebut sangat mempengaruhi kekuatan pancaran cahaya petromaks. Hal ini mendorong kami untuk mengamati pancaran cahaya petromaks dan faktor yang mempengaruhinya.

\section{METODE PENELITIAN}

Pengamatan ini dilakukan dengan menggunakan metode percobaan dengan fokus pada pengukuran cahaya lampu petromaks merek Butterfly. Pengukuran dilakukan pada malam hari di saat bulan mati, dengan anggapan bahwa tidak ada cahaya lain selain petromaks. Tekanan udara dalam tabung minyak adalah maksimal (30 psi) dengan isi tabung 1 liter minyak tanah.
Iluminasi cahaya diukur dengan Lux meter, ke arah samping (sudut 900) mulai dari titik sumber cahaya kemudian bergeser ke samping kanan atau ke kiri dengan interval jarak 1 meter sampai pada jarak dimana nilai iluminasi cahaya yang diukur adalah nol. Pengukuran ini dilakukan pengulangan sebanyak 3 kali. Tahapan kerja yang sama dilakukan pada penyalaan lampu petromaks dengan tudung dan tanpa tudung.

Untuk menganalisa penurunan iluminasi cahaya (pemudaran atau koefisien atemuasi) dipakai persamaan Burger (Dalam Nikorov, 1975) sebagai berikut:

$$
I_{x}=I_{0} \cdot e^{-k x}
$$

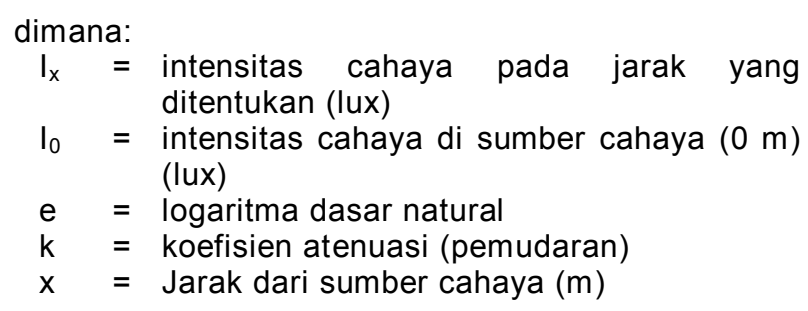

Perhitungan koefisien pemudaran (k) maka dipakai persamaan regresi exponensial dengan bantuan Software Excel.

\section{HASIL DAN PEMBAHASAN}

Hasil pengukuran iluminasi cahaya lampu petromaks yang memakai tudung dan tanpa tudung dapat dilihat pada Tabel 1 dan 2. 
Analisa Sebaran Iluminasi Cahaya Petromaks

Tabel 1. Hasil pengukuran iluminasi cahaya lampu petromaks dengan tudung (kap)

\begin{tabular}{|c|c|c|c|c|c|}
\hline \multirow{2}{*}{$\begin{array}{l}\text { No } \\
\text { Urut }\end{array}$} & \multirow{2}{*}{$\begin{array}{c}\text { Jarak } \\
(\mathrm{m})\end{array}$} & \multicolumn{3}{|c|}{$\begin{array}{c}\text { Iluminasi Cahaya } \\
\text { Lampu Petromax (lux) }\end{array}$} & \multirow{2}{*}{$\begin{array}{l}\text { Iluminasi } \\
\text { Rata-rata } \\
\text { (lux) }\end{array}$} \\
\hline & & 1 & 2 & 3 & \\
\hline 1. & 0 & 195,1 & 198,3 & 198,6 & 197,33 \\
\hline 2. & 1 & 38,0 & 38,0 & 38,7 & 38,45 \\
\hline 3. & 2 & 14,1 & 15,1 & 15,0 & 14,73 \\
\hline 4. & 3 & 5,5 & 8,2 & 8,2 & 7,30 \\
\hline 5. & 4 & 3,2 & 3,3 & 3,3 & 3,26 \\
\hline 6. & 5 & 1,3 & 1,2 & 1,2 & 1,23 \\
\hline 7. & 6 & 0,4 & 0,4 & 0,1 & 0,30 \\
\hline 8. & 7 & 0,2 & 0,3 & 0,1 & 0,20 \\
\hline 9. & 8 & 0,1 & 0,1 & 0,1 & 0,10 \\
\hline 10. & 9 & 0,1 & 0,1 & 0,1 & 0,10 \\
\hline 11. & 10 & 0,1 & 0,1 & 0,1 & 0,10 \\
\hline
\end{tabular}

Pada Tabel 1 terlihat bahwa iluminasi cahaya pada sumber diketahui, sebesar 197,33lux. Kemudian iluminasi cahaya terlihat menurun menurut jarak pengukuran. $\mathrm{Ni}$ lai terendah $(0,1$ lux $)$ dicapai pada jarak $8 \mathrm{~m}$ dari sumber cahaya.

Tabel 2. Hasil pengukuran iluminasi cahaya lampu petromaks yang tidak memakai tudung (tanpa kap)

\begin{tabular}{|c|c|c|c|c|c|}
\hline \multirow{2}{*}{$\begin{array}{l}\text { No } \\
\text { Urut }\end{array}$} & \multirow{2}{*}{$\begin{array}{c}\text { Jarak } \\
(\mathrm{m})\end{array}$} & \multicolumn{3}{|c|}{$\begin{array}{c}\text { Iluminasi Cahaya } \\
\text { Lampu Petromax (Ix) }\end{array}$} & \multirow{2}{*}{$\begin{array}{c}\text { Iluminasi } \\
\text { cahaya } \\
\text { Rata-rata (Ix) }\end{array}$} \\
\hline & & 1 & 2 & 3 & \\
\hline 1 & 0 & 177,1 & 183,1 & 175,1 & 178,43 \\
\hline 2 & 1 & 41,6 & 41,0 & 41,5 & 41,36 \\
\hline 3 & 2 & 18,5 & 18,4 & 18,6 & 18,50 \\
\hline 4 & 3 & 10,3 & 10,5 & 10,4 & 10,40 \\
\hline 5 & 4 & 6,7 & 6,6 & 6,7 & 6,67 \\
\hline 6 & 5 & 4,6 & 4,5 & 4,4 & 4,50 \\
\hline 7 & 6 & 3,2 & 3,3 & 3,1 & 3,20 \\
\hline 8 & 7 & 2,3 & 2,4 & 2,3 & 2,33 \\
\hline 9 & 8 & 1,8 & 1,9 & 1,8 & 1,83 \\
\hline 10 & 9 & 1,5 & 1,6 & 1,5 & 1,53 \\
\hline 11 & 10 & 1,2 & 1,2 & 1,2 & 1,20 \\
\hline 12 & 11 & 1,0 & 1,0 & 0,9 & 0,96 \\
\hline 13 & 12 & 0,8 & 0,7 & 0,1 & 0,53 \\
\hline 14 & 13 & 0,7 & 0,1 & 0,1 & 0,30 \\
\hline 15 & 14 & 0,6 & 0,1 & 0,1 & 0,26 \\
\hline 16 & 15 & 0,5 & 0,1 & 0,1 & 0,23 \\
\hline 17 & 16 & 0,4 & 0,1 & 0,1 & 0,20 \\
\hline 18 & 17 & 0,3 & 0,1 & 0,1 & 0,16 \\
\hline 19 & 18 & 0,2 & 0,1 & 0,1 & 0,13 \\
\hline 20 & 19 & 0,2 & 0,1 & 0,1 & 0,13 \\
\hline 21 & 20 & 0,1 & 0,1 & 0,1 & 0,10 \\
\hline 22 & 21 & 0,1 & 0,1 & 0,1 & 0,10 \\
\hline 23 & 22 & 0,1 & 0,1 & 0,1 & 0,10 \\
\hline 24 & 23 & 0,1 & 0,1 & 0,1 & 0,10 \\
\hline 25 & 24 & 0,1 & 0,1 & 0,1 & 0,10 \\
\hline 26 & 25 & 0,1 & 0,1 & 0,1 & 0,10 \\
\hline 27 & 26 & 0,1 & 0,1 & 0,1 & 0,10 \\
\hline 28 & 27 & 0,1 & 0,1 & 0,1 & 0,10 \\
\hline
\end{tabular}

Pada Tabel 2 menunjukan distribusi iluminasi cahaya lampu petromaks yang tidak memakai tudung. Dari Tabel tersebut terlihat bahwa iluminasi cahaya di sumber cahaya tercatat sebesar 180,1lx. Distribusi iluminasi cahaya lampu petromaks tanpa tudung ternyata lebih jauh ke samping dibandingkan dengan lampu yang memakai tudung, dimana iluminasi terendah dicatat pada jarak $28 \mathrm{~m}$.

Menurut Yami (1987) bahwa iluminasi cahaya akan semakin menurun jika jarak dari sumber cahaya semakin jauh.

Nilai pemudaran iluminasi cahaya lampu petromaks yang dihitung dengan persamaan menurut hukum Burger dapat digambarkan seperti pada Gambar 1 dan 2.

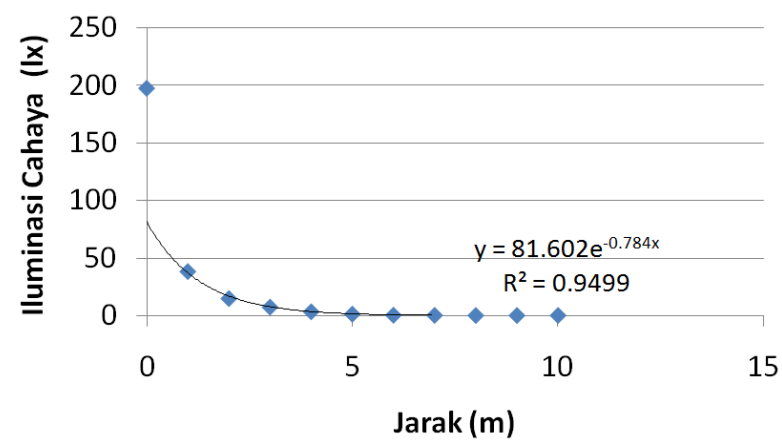

Gambar 1. Distribusi penurunan nilai iluminasi cahaya rata-rata dari lampu petromaks dengan tudung.

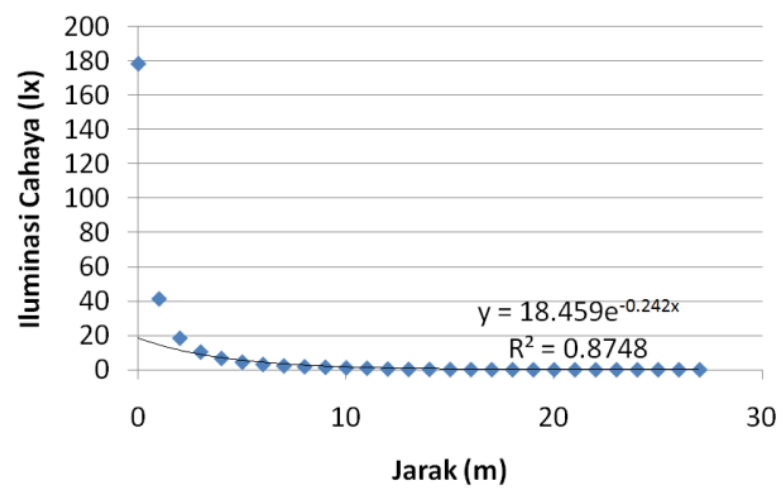

Gambar 2. Distribusi penurunan nilai iluminasi cahaya rata-rata dari lampu petromaks tanpa tudung.

Pada Gambar 1 dan 2 dapat dilihat adanya iluminasi cahaya lampu menurun secara eksponensial. Hasil perhitungan menunjukkan nilai koefisien pemudaran atau atenuasi untuk lampu petromaks yang memakai tudung adalah sebesar 0,78 (Gambar 1) dan untuk lampu petromaks tanpa tudung adalah sebesar 0,23 (Gambar 2).

Kemudian nilai koefisien $\mathrm{k}$ tersebut yang sudah diperoleh dimasukan kedalam persamaan Hukum Burger untuk memper- 
oleh kurva menurut fungsi exponensial dalam jarak tertentu seperti terlihat pada Gambar 3 dan 4.

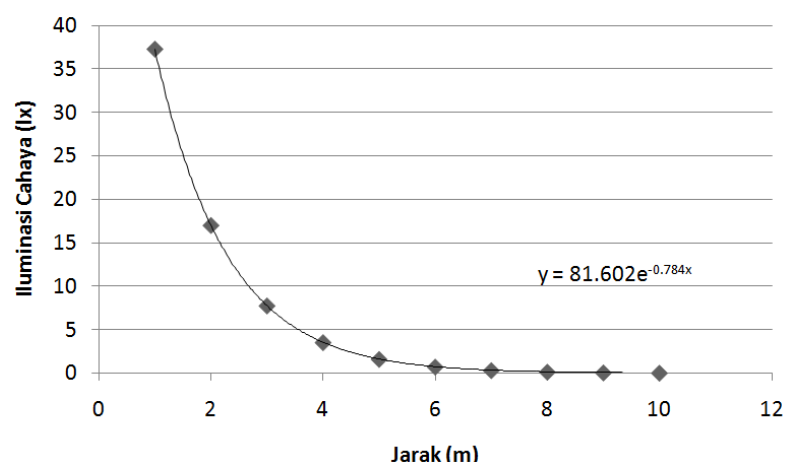

Gambar 3. Pola hubungan antara iluminasi cahaya lampu petromaks bertudung dengan jarak pengukuran.

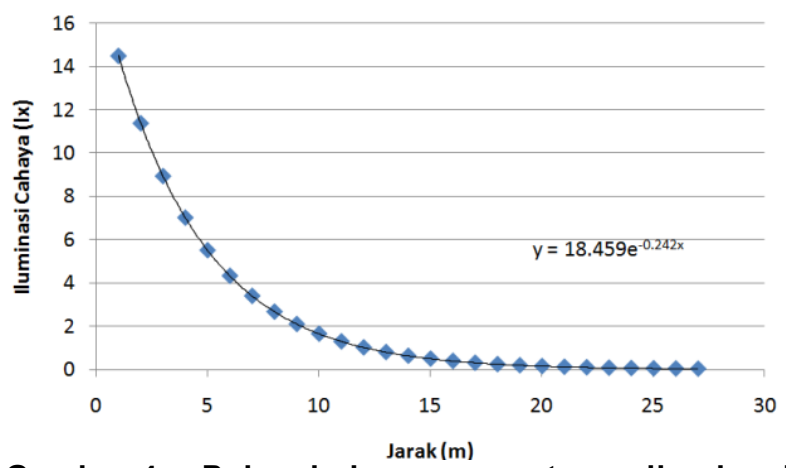

Gambar 4. Pola hubungan antara iluminasi cahaya lampu petromaks tanpa tudung dengan jarak pengukuran.

Menurut Baskoro (1999) bahwa nilai iluminasi cahaya suatu sumber cahaya akan menurun dengan semakin meningkatnya jarak dari sumber cahaya tersebut dan nilainya akan berkurang apabila cahaya tersebut masuk ke dalam air.

Pancaran cahaya petromaks ternyata lebih banyak menyebar ke samping. Pancaran cahaya ke arah bawah terhalang oleh tangki minyak tanah (Puspito, 2006). Menurut hasil penelitian dari ahli ini, bahwa pemakaian tudung pada lampu petromaks dapat dimanfaatkan sebagai alat bantu untuk mengumpulkan ikan dalam perikanan Bagan. Hal ini disebabkan karena tudung dapat memfokuskan cahaya ke arah bawah dan mengurangi banyaknya cahaya yang menyebar di luar kerangka alat tangkap.

Hasil penelitian dari Puspito, (2006) menunjukkan bahwa lampu petromaks dengan sisi miring tudung lampu sebesar 450 dapat menghasilkan posisi jatuh cahaya yang efektif yakni arah pancar cahaya horizontal yang tidak terlalu luas.

\section{KESIMPULAN}

Kesimpulan yang dapat ditarik dari penelitian ini adalah:

1. Iluminasi cahaya di titik sumber cahaya untuk lampu petromaks yang bertudung dan tanpa tudung masing-masing 197,33 Ix dan 178,43 Ix.

2. Iluminasi cahaya lampu petromaks yang bertudung ternyata memiliki area bidang pancar yang lebih kecil $( \pm 8 \mathrm{~m})$ dibandingkan dengan lampu petromaks yang tidak bertudung $( \pm 21 \mathrm{~m})$.

3. Iluminasi cahaya lampu petromaks yang diukur ternyata mengalami pemudaran menurut jarak pengukuran dari sumber cahaya. Hasil pengukuran konstanta pemudaran (atenuasi) cahaya menunjukan koefisien atenuasi yang ditemukan adalah masing-masing 0,78 untuk cahaya lampu petromaks bertudung dan 0,24 untuk lampu petromaks tanpa tudung.

4. Penggunaan penutup (tudung) dapat memfokuskan cahaya ke arah bawah dan mengurangi banyaknya cahaya yang menyebar ke samping.

\section{DAFTAR PUSTAKA}

Baskoro, M. S. 1999. Capture Process oh The Floated Bamboo-Platform Liftnet with Light Attraction (Bagan). Graduate School of Fisheries, Tokyo University of Fisheries. Doctoral Course of Marine Sciences and Technology. P 149

Cayless. M.A and A. M. Marsden. 1983. Herring Behaviour in Light and Dark. in Light and Life in the sea Ed. By P.J.Herring, Anthony K. Cambell, M Whitfield and L. Maddock. Cambridge University Press. Cambridge. P 205-227.

Nikorov, 1975. Interaction of Fishing Geor with Fish attraction. Israel:Jerusalem Ketter Pres, $216 p$

Picasouw, J. 2005. Lampu Petromak Sebagai Alat Bantu Penangkapan Ikan. Warta Oseanografi. Vol. XIX. No. 3. JulliSeptemeber. Hal. 25-28.

Puspito,G., 2006. Kajian Teoritis dalam Merancang Tudung Petromaks. Mangrove dan Pesisir, Vol. VI, No. 3. Hal. 1- 9. 
Subani, W. 2003. Penggunaan Lampu sebagai alat bantu penangkapan ikan. Laporan Penelitian Perikanan Laut. Balai Penelitian Perikanan Laut. Departemen Pertanian. Jakarta. Hal 45-55
Woodhead, A.D. 1996. The Behaviour of Fish in Relation to Light in the Sea. Oseanogr. Mar. Biol.Ann. Rev, 4: p 334-407

Yami. B. 1988. Attracting Fish with Light. Roma : FAO 